\title{
Ensino de filosofia na era da pós-verdade
}

\author{
Teaching of Philosophy \\ in the post-truth politics era
}

\section{Resumo}

Neste texto, procuramos situar o ensino de filosofia em meio ao panorama da pósverdade, enquanto novo horizonte de comunicação hegemônico de nossa época. Apresentamos algumas características centrais e nefastas da pós-verdade, como a polarização comunicativa das bolhas digitais e a natureza viral das fakenews, como decorrentes, sobretudo, da ampliação do controle de dados na internet. Ao longo desta apresentação, nos perguntamos sobre as relações que esses fenômenos guardam com a filosofia: a relação que a pós-verdade guarda com a verdade; como situar o problema numa compreensão filosófica mais ampla acerca da contemporaneidade; e como pensar a potência dos regimes de verdade construídos pela filosofia enquanto uma estratégia pedagógica imunitária frente ao caos da "era da pós-verdade".

Palavras-chave: Pós-verdade, regimes de verdade, ensino de filosofia.

\begin{abstract}
In this text, we try to situate the teaching of philosophy in the midst of the panorama of the post-truth politics, as a new horizon of hegemonic communication of our time. We present some central and harmful characteristics of post-truth politics, such as the communicative polarization of digital bubbles and the viral nature of fakenews, as mainly the result of the expansion of data control over the Internet. Throughout

\footnotetext{
* Doutor em Filosofia e professor da Faculdade de Educação da UFRJ. E-mail: filcepps@gmail.com.

** Doutora em Filosofia pela UFRJ. E-mail: raquelrocharodrigues9@gmail.com.
}

Recebido em: 13/03/2019 e Aceito em: 30/09/2019. 
this presentation, we ask ourselves about the relations that these phenomena keep with philosophy: the relation that the post-truth politics holds with truth; how to situate the problem in a broader philosophical understanding of contemporaneity; and how to think the potentiality of the philosophical constructed truth regimes as an immune pedagogical strategy in the chaos of the "post-truth politics era".

Key words: Post-truth politics, truth regimes, teaching of philosophy.

Horizonte de nossa atualidade, a pós-verdade ${ }^{1}$ desafia, de modo inédito, a autocompreensão da tarefa da filosofia. Pensamos a pós-verdade como sendo o horizonte de desvario digital de uma humanidade enredada numa disputa diária, intensa e aparentemente descontrolada entre narrativas muitas vezes delirantes; uma disputa na qual estão em jogo, em grande medida, os processos de secularização da cultura, de construção dos direitos humanos e de luta por justiça social. Pós-verdade é o nome para a potencialização em larga escala - oportunizada pelas redes digitais - do racismo, do fundamentalismo religioso, do sexismo, da misogenia, da lgbtfobia e dos mais diversos preconceitos e de tentativas de justificativas da manutenção das desigualdades sociais, sob a aparência de uma disputa discursiva, via de regra diretamente promovida por plataformas político-econômicas retrógradas, "em nome do povo e das pessoas de bem". Essa captura da atenção e das energias, de uma minoria barulhenta a uma maioria silenciosa, amplifica os confrontos ideológicos num processo que tende a reforçar dogmaticamente, e de modo inédito, as "verdades" de cada bolha ideológica, à direita e à esquerda. As pretensões de legitimidade do discurso científico, dos processos meritocráticos de seleção de expertises ou, ainda, de circuitos culturais em conflito, se veem radicalmente diluídas na era da pós-verdade, ultrapassadas pelos novos mecanismos de fabricação dos consensos parciais das bolhas digitais, com características em grande parte radicalmente diferentes do debate público conhecido até então.

1 O termo "pós-verdade" torna-se popular nas eleições norte-americanas de 2016, motivo pelo qual o Oxford Dictionary o elege como "palavra do ano". A definição atribuída pelo dicionário refere-se a "um adjetivo que se relaciona com ou denota circunstâncias nas quais fatos objetivos tem menos influência em moldar a opinião pública do que apelos à emoção e a crenças pessoais." (tradução nossa). 
As bolhas digitais vêm transformando, de modo aparentemente irreversível, não apenas a dinâmica da disputa política-ideológica, mas também a relação com a verdade. No debate público pré-digital, mediado pelas instituições e pela mídia tradicional (jornal, rádio, TV), de formato analógico, "a verdade", os saberes e valores, sempre atravessados por confrontos entre narrativas e jogos de poder, tendem a responder, mal ou bem, a uma lógica de reconhecimento, onde o peso do trabalho, da autoridade de uma obra, de um autor, de uma boa profissional, das pesquisas, etc, fala mais alto, mesmo que essa lógica raramente prevaleça nas tomadas de decisão, em função de interesses políticos e econômicos daqueles que detém influência e poder. Neste cenário, a opinião pública é mais permeável à circulação de opiniões matizadas, qualificadas, que servem para constranger as tomadas de decisão. Essa lógica torna-se cada dia mais insignificante. No consenso-dogma-bolha-digital, os únicos extratos da opinião pública que importam são os dos eleitores e consumidores, com fluxos digitalmente mensurados e manipulados por algoritmos.

Neste sentido, o consenso-dogma-bolha-digital radicaliza dramaticamente o que o velho circuito dos mass media tem de pior: a submissão aos interesses governamentais e econômicos. Com o processo de monopolização comercial-algorítmico das redes sociais, a possibilidade de comunicação horizontal, plural e sem fronteiras da internet perdeu espaço para a personalização dos conteúdos. A análise de dados que produz os filtros-bolhas é utilizada predominantemente para atender aos interesses do mercado e dos políticos. Em comparação com os demais meios de comunicação, a mídia digital é, hoje, o veículo mais eficaz de manipulação das massas. Ao permitir uma comunicação em tempo real mais ativa, direta e dinâmica, ou interativa, a internet modificou a forma de narrar os fatos, as notícias, e de produzir conteúdos de entretenimento, tornando-se a principal via de informação da maior parte da população mundial. Se antes, na era dos mass media, o cinema, os canais de televisão e rádio eram os principais veículos de manipulação das massas e indutores de novos modos de vida, estes são, hoje, as redes sociais, os blogs, os portais de entretenimento e de notícias. Tendemos a ficar cada vez mais isolados em nossas bolhas digitais, o que nos torna, em grande medida, mais reativos apenas àqueles conteúdos que nos são indicados, selecionados, reforçando nossas crenças e sentimentos, restringindo ou polarizando nossas interações com pessoas que não compartilham os mesmos valores e modos de vida. A fácil acessibilidade digital, através de tablets e smartphones, nos submete, ainda, a uma híper-exposição-excitação antes inimaginável, com fortes repercussões em todos os níveis de nossa existência. 
A fabricação dos consensos-dogma-bolha-digital pelo dataísmo ${ }^{2}$ modifica nossa relação com a verdade na medida em que a informação gerada a partir dos fluxos digitais não é mais resultado de uma comunicação narrativa, mas de uma análise de dados, realizada nos bastidores algorítmicos, que servem de base para gráficos informacionais. Com o dataísmo, observa-se um certo esvaziamento do sentido da linguagem. Se tudo é mensurado, reduzido a números, linguagem de códigos, o sentido das palavras e da língua é esvaziado, ou reduzido a um mínimo de informação: não interessa o sentido das narrativas compartilhadas, apenas a informação que pode ser obtida, codificada e simplificada em dados, números, estatísticas. Ao contrário do que possa parecer no embate das redes, a comunicação, em sua abstração algorítmica, não é baseada em qualquer noção de verdade, ou numa verdadeira disputa pela verdade - isto é, numa disputa que pressuponha seleção de informações relevantes, protocolos de argumentação, procedimentos hermenêuticos, etc. Ela está baseada no alcance do conteúdo publicado a partir da quantidade de likes e compartilhamentos na internet. As informações movidas pelos dados reforçam conceitos já estabelecidos de acordo com as análises algorítmicas e transformam a comunicação em um debate entre iguais-idênticos, em que os confrontos ideológicos ou a produção de um "discurso de verdade" funcionam apenas como reafirmação do mesmo e negação automática da diferença. É a produção daquilo que Byung-Chul Han denomina "inferno do igual". ${ }^{3}$ As práticas do discurso estão submetidas ao que é induzido nas redes e impulsionado pelo uso de hastags, desafios de fotos, memes, gírias, correntes de Whatsapp, etc.

A massa de dados e de informações que hoje cresce de forma desmedida desvia imensamente a ciência da teoria, do pensamento. Em si, as informações são positivas. A ciência positiva baseada em dados (ciência Google), que se esgota no nivelamento e comparação de dados, põe fim à teoria em sentido enfático. Ela é aditiva ou detectiva; não é narrativa nem hermenêuta. (...) A massa de informações, hoje, ao contrário, atua como modo deformativo. ${ }^{4}$

2 Por dataísmo compreendemos a ciência que emerge a partir do acúmulo de dados cooptados na internet e armazenados em datacenters. No dataísmo, tudo é mensurado, medido, convertido em dados e analisado para servir de base na produção e indicação de conteúdos na web.

3 Han utiliza o termo "inferno do igual" para indicar como o controle de dados homogeniza a sociedade de tal forma a excluir a ideia de confronto ou a noção de outro enquanto alteridade. Agonia do Eros e Sociedade da transparência, ambos publicados pela Editora Vozes em 2017, são dois importantes trabalhos acerca de como a sociedade vem sendo transformada e modelada pela internet de acordo com os interesses das empresas e dos governos.

4 Han, B-C. A agonia do Eros, RJ: Editora Vozes, 2017, p.87-88. 
Essa deformação assume, porém, o conteúdo preciso da radicalização da colonização jornalística e policial da vida ordinária e da política, a reboque da capilaridade difusa e universal das redes de controle, econômicas, financeiras, digitais. Dado este cenário muito brevemente esboçado, cabe perguntar: a filosofia, enquanto um "discurso sobre a verdade", pode ajudar a superar esse cenário babélico?

Comecemos com a questão histórico-filosófica acerca da própria afirmação de que entramos numa "era da pós-verdade". Mal comparando, acontece com a ideia de pós-verdade algo parecido com o que acontece com a ideia de antropoceno. A pergunta acerca do antropoceno é se haveria critérios geológicos suficientes para dizer que saímos do holoceno. A época do holoceno começa com a última grande glaciação, há 11,5 milhões de anos atrás e não há nada, segundo o mainstream da geologia, a indicar que uma mudança dessa magnitude esteja ocorrendo atualmente. E é bem possível que os seres humanos não mais existam quando isso acontecer. Haveria, na escala das ciências humanas, mudança sistêmica equivalente à que se quer reconhecer, no debate sobre as mudanças climáticas, com a ideia do antropoceno? Haveria mudança significativa nas estruturas sociais e políticas, nas produções econômicas, institucionais e discursivas, com relação àquelas estabelecidas pela modernidade? Faz sentido falar que entramos numa "era da pós-verdade"? Provisoriamente, assumimos um posicionamento estratégico semelhante àquele que consideramos válido para a questão do antropoceno: trata-se antes de mais nada de uma posição política. Mesmo que os diagnósticos acerca do aquecimento do planeta e de suas consequências apocalípticas estejam errados (e nós não achamos que estejam), eles implicam questões essenciais para o presente, questões filosóficas, éticas, econômicas, políticas, relativas a formas de vida já em si mesmas insustentáveis. Exemplos não faltam: dos grandes crimes ambientais, com centenas de vítimas, como Mariana e Brumadinho, ao aumento vertiginoso da poluição e dos índices de violência diária no campo e nas grandes cidades. Não se trata de "causalidades", mas de um amálgama de fatos e efeitos catastróficos interligados.

Pós-verdade conjuga dois fenômenos diferentes, mas interligados; um, moderno, industrial: a crescente intensificação e concentração do estabelecimento de "verdades" nas mãos de alguns poucos e poderosos setores interconectados (grandes corporações midiáticas em associação com poderes financeiros, políticos e jurídicos); o segundo, contemporâneo e pós-industrial: a algoritmização, a produção de hiperlinks e o excesso descontrolado (para o usuário) de informações, sobretudo a partir do aparecimento das redes 
sociais, mas também em sistemas decisórios de grande complexidade, como os investimentos de riscos na área financeira e bolsas de mercados futuros (baseados nos tradings economics).

A noção de pós-verdade reafirma e aprofunda os diagnósticos apenas aparentemente antagônicos de Habermas, Lyotard e Foucault acerca da contemporaneidade. Com relação ao primeiro, a pós-verdade significaria uma radicalização da autonomização das esferas da vida (Weber). Na perspectiva de Lyotard, ela radicalizaria o processo de deslegitimação do saber em que se enredaram as ciências, desde o fim do século XIX, com o fim do idealismo especulativo e o enfraquecimento das promessas do iluminismo. ${ }^{5} \mathrm{Com}$ relação a Foucault, a pós-verdade, enquanto fenômeno da cibercultura, deve ser analisada como um novo e central mecanismo do controle biopolítico. À luz dessa relação entre biopolítica e a cibercultura como mecanismo de controle, intelectuais contemporâneos como Antoinette Rouvroy e Thomas Berns apontam para a formação de uma nova forma de governamentalidade baseada nos algoritmos, em que a pós-verdade é compreendida como parte da formação de discursos baseados em números e manipulação das massas. ${ }^{6}$

A produção dos saberes, da verdade e dos discursos vê-se, por toda parte, reconfigurada pelas quantificações e processos analíticos da Big Data. ${ }^{7}$ A produção de discursos na rede distancia-se, em grande medida, daquilo que, até então, se entendia usualmente como produção dos discursos com pretensão de verdade. Não é mais o discurso, a palavra, que valida o que é verdadeiro, mas o dado, a análise algorítmica baseada nos números; isto é, o que importa são dados obtidos através do datamining. ${ }^{8}$ Com as novas relações discursivas estabelecidas pela internet, via redes sociais e suas hashtags, a sociedade do espetáculo alcança um outro patamar de influência sobre as massas. O Twitter, com seu modelo de comunicação resumida a 140 caracteres, ou o modo de

5 Com relação aos dois primeiros, como muito bem notou Alberto Gualandi, "o que separa profundamente Habermas de Lyotard não é o diagnóstico de crise, mas as soluções que eles propuseram para essa situação". Gualandi, A. Lyotard, SP: Estação Liberdade, 2007.

6 Ver Rouvroy, A. \& Berns, 2015 e Rouvroy, A. Mise en (n)ombres de la vie même : face à la gouvernementalité algorithmique, repenser le sujet comme puissance, Mediapart, 2012.

7 O termo Big data designa a cooptação e armazenamento do fluxo de dados gerados na internet e serve de base para mineração de dados (datamining) e análise de dados (dataísmo) de acordo com os interesses das empresas detentoras dos monopólios de dados.

8 O datamining ou mineiração de dados é um conjunto de técnicas e ferramentas de coleta, acúmulo e análise dados. A expressão surge nos anos $90 \mathrm{em}$ comunidades de base de dados para designar a etapa analítica do processo conhecido como KDD (Knowledge Discovery in Data bases). 
comunicação através de stories que somem após 24h, comumente usados em aplicativos como Instagram, Snapchat e Facebook, podem ser vistos como o protótipo dessa comunicação rápida e sucinta que, a médio e longo prazo, vem tornando a comunicação cada vez mais esvaziada de sentido. É a informação pela informação, reconfigurando a qualidade, a motivação e a duração da reflexão; uma notícia apaga a outra na velocidade com a qual as hashtags, memes e vídeos curtos viralizam. Cada vez mais imagética, a comunicação se reduz a signos descontextualizados e frases de efeito que contribuem para a construção de microdiscursos, em meio a uma grande poluição visual, dificultando a construção de um pensamento reflexivo e coletivo, igualmente prejudicado pela tática política da cortina de fumaça, utilizada por governos na intenção de desviar o foco das ações governamentais.

A pós-verdade é esse campo de informações esvaziadas de sentido. Ela molda a opinião pública de acordo com apelos emocionais e ideológicos, a partir de imagens e frases de efeito que têm como principal função provocar um efêmero e reiterativo sentimento de identificação ou repulsa ao conteúdo exposto. Vídeos e áudios cuidadosamente editados, manipulação de imagens, memes e jargões espalhados e repetidos à exaustão contribuem para enredar a população em uma teia de fakenews, e de reações a elas, manipuladas de acordo com os interesses de cada grupo, em especial daqueles que detêm maior poder de mobilização e investimentos. Os impactos das fakenews são cada vez mais evidentes na influência crescente da internet nos processos eleitorais em todo o mundo, e no uso das redes sociais como uma das principais ferramentas de governo, tornando a disputa político-cultural em grande medida refém de sua frenética produção.

Mas, se as dimensões sistêmicas e pragmáticas que formam a pós-verdade podem ser entendidas, de certo modo, como o ápice do fim da Verdade com 'v' maiúsculo (como sintoma da secularização e do enfraquecimento das metanarrativas; da "morte de Deus" e dos abalos da metafísica; ou, ainda, como uma mutação e radicalização da biopolítica), elas não deixam de reavivar e estimular, paradoxalmente, todos os seus jogos e fantasmas. É parte constitutiva e essencial da pós-verdade a luta em torno da Verdade. É dessa luta que se alimentam as fakenews, do recrudescimento das disputas religiosas e políticas ao paradoxal e mortífero estado de guerra globalizado, que intensifica por toda a parte a insegurança em nome da segurança. ${ }^{9}$

9 Ver Mbembe, A. Politiques de l'inimitié, Paris: Éditions La Découverte, 2016. 
Apresentadas, ainda que muito brevemente, essas características gerais, o principal desafio da filosofia seria o de vislumbrar uma pedagogia filosófica capaz de servir de antídoto a essa ubiquidade avassaladora da pós-verdade. De certo modo (essa é a nossa aposta), todo exercício filosófico não-dogmático é uma espécie de resistência imunitária aos paradoxos da pós-verdade, incluindo nesse não-dogmatismo a compreensão de que todo discurso filosófico carrega em si um certo regime de verdade, uma potência de desvelamento que é, ao mesmo tempo, ficcional, performativa e política. ${ }^{10}$ Isto é, nem todo filosofar seria capaz de desestabilizar as ilusões da pós-verdade, mas somente um exercício de pensamento não-dogmático e de radical questionamento da própria noção de verdade, porque capaz de se ver a si mesmo como teorização provisória, performática, política, modelos possíveis, "ferramenta" (como na famosa imagem que Deleuze oferece para a filosofia de Foucault) ou "pontos de referências" (Rancière). ${ }^{11}$

O jogo ordinário em torno da Verdade paradoxalmente alimentado pela pós-verdade não responde somente a uma enigmática intensificação do jogo ideológico; ele não é, em outras palavras, uma mera intensificação da velha mentira em política. A férrea disputa pela verdade na era da pós-verdade é mais do que um simulacro da crença em uma verdade transcendente - supostamente baseada em uma fundamentação científica ela mesmo sem fundamento -, ela é, em um de seus aspectos essenciais, a recusa obstinada dos regimes de verdade que (em diálogo com as ciências e as artes) a filosofia avança, com toda a sua lentidão, cuidado e precariedade. Com esse outro tempo, a filosofia paradoxalmente, e desde sempre, se adianta aos seus detratores, desde os cínicos, desde os céticos, até Nietzsche, Foucault, Derrida, Rancière e tantos outros e outras. A filosofia sempre encarou a possibilidade de que a verdade não seja nada, no duplo sentido da expressão: tanto no sentido de que ela pode não existir enquanto uma presença, entidade estável; como no de que ela não é nada, ela é sempre alguma coisa - uma ilusão que seja.

Com Nietzsche, seria preciso acrescentar que a recusa aos regimes de verdade, a recusa à filosofia é, afinal, a dificuldade em lidar com a questão do

10 Devemos à professora Laurence Cornu esta tese da importância dos regimes de verdade para pensar a relação da filosofia com a pós-verdade, desenvolvida em comunicação apresentada no "IV Congreso Latinoamericano de Filosofía de la Educación: Desafíos de la Educación en América Latina: memoria y prospectiva", no Simpósio "El lugar de la filosofía de la educación en la formación: los desafíos de la 'post-verdad", realizado em Buenos Aires, em 2017.

11 Ver Foucault, M. Os intelectuais e o poder. Entrevista entre Michel Foucault e Gilles Deleuze, in Microfisica do poder, RJ: Graal, 1979, p.71; e Rancière, J. La méthode de l'égalité, Paris: Bayard, 2012, p.152. 
valor da verdade. Sustentar a verdade como valor supremo, que serve para julgar tudo o mais (fantasmagoria metafísica que a pós-verdade reativa em meio ao seu burburinho rasteiro) seria, como na bela imagem do nono aforisma de Humano, demasiado humano, agir como um navegante que, na tempestade, quer tirar proveito da análise química da água. A pós-verdade, que dispõe de supostos fatos a seu bel prazer e ignora não tanto as "verdades científicas", mas antes os seus métodos, ao recusar os protocolos mais básicos de dúvida e investigação, projeta uma carga moral em torno da adesão às verdades em disputa. Trata-se de um jogo que não corresponde à mera escolha subjetiva, mas ao mecanismo ardiloso em que a ideia de verdade única é ao mesmo tempo negada e afirmada de modo moral, como um critério-bolha-identitário de pertencimento. A pós-verdade mina os protocolos de verdade dos "ambientes científicos e letrados", impondo a estes o desespero (dada sua total impotência diante dos processos algorítmicos) perante o desrespeito à complexidade do real, pela ignorância ou negação da importância e da precariedade dos regimes de verdade que os seres humanos são capazes de construir. Ao fazê-lo, ela reforça, mesmo que a contragosto, a reprimenda moral arremessada contra o "homem inculto e reacionário", aquele que Nietzsche chamou de "cruel" e "atrasado", gesto intimamente relacionado ao pesadelo iluminista de querer impor o valor da verdade como medida para a vida, principal miragem da qual se serve a pós-verdade.

Nietzsche não cansou de nos advertir contra este erro, como no aforisma 43 de Humano, demasiado humano, intitulado "Homens cruéis, homens atrasados":

Devemos pensar nos homens que hoje são cruéis como estágios remanescentes de culturas passadas: a cordilheira da humanidade mostra abertamente as formações mais profundas, que em geral permanecem ocultas. São homens atrasados, cujo cérebro, devido a tantos acasos possíveis na hereditariedade, não se desenvolveu de forma vária e delicada [grifo nosso]. Eles mostram o que todos nós fomos, e nos infundem pavor, mas eles próprios são tão responsáveis como um pedaço de granito é responsável pelo fato de ser granito [grifo nosso]. Em nosso cérebro também devem se achar sulcos e sinuosidades que correspondem àquela mentalidade, assim como na forma de alguns órgãos humanos podem se achar lembranças do estado de peixe. Mas esses sulcos e sinuosidades já não são o leito por onde rola atualmente o curso do nosso sentimento. ${ }^{12}$

12 NIETZSCHE, F. Humano, demasiado humano, trad. P.C Souza, São Paulo: Cia. das Letras, 2005, p.48. 
Em nossa leitura, escusamos o fisiologismo evolucionista e redutor da explicação. O que importa, nesta passagem, em primeiro lugar, é a indicação do sentimento, enquanto amálgama de forças que compõem a vida, como responsável pela sua variedade e delicadeza. Importa, em segundo lugar, o caráter amoral da variedade da vida: um reacionário é tão responsável por sua condição como um granito é responsável pelo fato de ser granito. Não se cura uma doença dos olhos ou da alma com argumentos. Alguém que queira convencer o outro de que suas crenças advêm de uma "compreensão atrasada da realidade" acaba por se igualar a este, mormente no ambiente algorítmico da pós-verdade.

Nosso desafio - parte essencial de uma pedagogia filosófica no reino da pós-verdade - é, portanto, admitir de saída que os regimes de verdade pouco podem frente à pós-verdade, seja somente porque as ondas algorítmicas geram um circo dos horrores de amor e ódio em torno da verdade. A única saída é fugir de tudo isso e construir nichos de confiança compartilhada e exercícios de regimes de verdade numa perspectiva igualitária, tal como nos sugere Jacques Rancière. Ainda que a aposta igualitária, segundo Rancière, sempre implique um jogo de razão contra razão, uma tomada de palavra e argumentação, o essencial aqui é a ruptura que este jogo produz na normalidade das relações de poder, a partir de uma relação de igualdade na alteridade que se estabelece desde o princípio. É exatamente o contrário o que acontece nos quadradinhos das redes sociais, nas disputas em torno da verdade carregadas de moralidade, onde o usuário é juiz e comentarista do que quiser, estimulado a manifestar, de modo mecânico e imediato, com likes e emojis, a pertinência ou impertinência do conteúdo: reforço imediato da informação decodificada, incapacidade de reinvenção do uso da palavra, sequestrado pelo formato pré-moldado e a rapidez do fluxo digital. As aparentes liberdade e igualdade de condições de enunciação nas redes digitais é todo o contrário da liberdade e da igualdade emancipadoras do animal literário que somos:

Um animal literário é aquele que tem seu destino alterado pelo poder das palavras, que altera a rota do animal social, gregário, comum. Quando há um momento politicamente forte, de certa forma a "politicidade" deste momento está relacionada à "literariedade”, quer dizer, a essa descoberta dos sujeitos como "seres falantes" (êtres parlants), do poder das palavras, o poder de tornar iguais os seres falantes. Toda a crise de consciência política forte se constitui de tomadas de consciência de seres falantes que interrompem toda a lógica da dominação, quando as palavras não têm 
mais a função exclusiva de designar os objetos ou de determinar ações. $O$ animal literário escapa da normalidade pela eficácia de palavras como "igualdade" ou "liberdade". 13

Mas, desde o ponto de vista de uma pedagogia filosófica, Rancière parece considerar que este "método da igualdade" do animal literário e sua perspectiva emancipadora não se traduz em nenhuma ação pedagógica institucional, escolar. Primeiro porque, como diz Jacotot, o povo não deve esperar de um governo (ou, poderíamos acrescentar, de qualquer grupo bem intencionado) algo que ele mesmo pode e deve conquistar por sua própria conta. Em segundo lugar, porque a escola republicana seria uma instituição onde todas as crianças já se encontrariam numa relação de relativa igualdade com respeito às normas, ao currículo, etc, isto é, num lugar de ócio (skholé) suficientemente protegido das demandas externas do mundo da produção. ${ }^{14}$ Seria preciso levar em conta, entretanto, que a trama da pós-verdade invade com força a escola (vide a onda do escola sem partido entre nós) e que sempre, e cada vez mais, o processo de ensino-aprendizado encontra-se atravessado por demandas crescentes de todo tipo: políticas, produtivas, comerciais e jurídicas, com respeito aos conteúdos, métodos e finalidades educativas. A pós-verdade se disputa cada vez mais cedo, também dentro da escola, e de modo cada vez mais feroz.

Para encurtar a história, poder-se-ia desejar que os limites de todo o imbróglio em torno da verdade, no reino da pós-verdade, fossem jurídicos, para logo em seguida constatar o limite de uma tal abordagem. Diante das disputas ideológicas em torno das decisões governamentais, assim como a respeito dos conflitos ordinários, acredita-se (à direita e à esquerda) que, no limite, os árbitros determinantes serão a política institucional e o Direito, e se (des)confia que estes tendem a impor parâmetros conservadores a qualquer exigência radical de igualdade. E todos não deixam de ter, em parte, razão. O Direito serve antes de mais nada ao Estado e à manutenção da ordem, ainda que, por vezes, sirva também para defender a justiça social. Grosso modo, a construção

13 Rancière, J. Os riscos da razão, entrevista, Folha de São Paulo, 10 de setembro de 1995.

14 Para o primeiro ponto, ver Rancière J. O mestre ignorante, cinco lições sobre a emancipação intelectual, BH: Autêntica, 2002; para o segundo, Rancière, J. École, Production, Égalité. In: X. Renou (ed.), L'école de la démocratie. Paris : Edilig Fondation Diderot, 1998. Uma tentativa de análise dessas questões encontra-se em Ceppas, F. Arte, educação e emancipação, AISTHE, Vol. VII, no 11, 2013. Para uma reconsideração recente do problema, ver Rancière, J. Emancipación intelectual y educación hoy, in González, P. y Celedón, G. (orgs), Reflexiones con Jacques Rancière, Valparaíso: Ed. UV de la Universidad de Valparaíso, 2016. 
de nichos de confiança compartilhada e exercícios de regimes de verdade numa perspectiva igualitária não deveria contar - ou não deveria contar em última instância - com o Estado de Direito. É preciso fugir também desta armadilha. Se, para o bem e para o mal, a Verdade transcendente do Estado de Direito é o fundamento último das democracias burguesas, sua principal prerrogativa de manutenção da ordem jurídica não escapa à lógica da pós-verdade. ${ }^{15}$

Claro, dizemos, "tem que haver alguma ordem! Nem tudo pode!" Mas esta é uma constatação trivial em todas as sociedades, mesmo nas sociedades sem Estado, como as sociedades indígenas. É sempre bom lembrar da natureza contingente do Estado de Direito, com seu aparato repressor e seus mecanismos de controle. ${ }^{16}$ Se, como pontifica Lévi-Strauss, ${ }^{17}$ nenhuma sociedade é melhor do que outra (ainda que isso não agrade ao esgrimista da pós-verdade, que confia no progresso), a transcendência de uma ordem superior desmorona. Uma ordem distinta, um "outro mundo", não é uma ideia delirante ou um sonho irresponsável. Ela é o correlato desta consciência difusa da mentira da transcendência do Direito como fundamentação última e intocável da ordem social. É somente diante desta aposta maior que compreendemos o sentido de uma pedagogia filosófica contra a pós-verdade, enquanto rejeição de uma esperança redentora no próprio fundamento da sociedade capitalista, da mítica absolutização de um Estado de Direito supostamente garantidor da democracia e do equilíbrio social.

A pós-verdade radicaliza o reconhecimento de que o Estado de Direito é incapaz de gerenciar os interesses particulares em conflito, de voracidade e ferocidade crescentes, mormente no cenário distópico-digital do neoliberalismo 4.0, em que se fundem os máximos controle e descontrole, violência e vigilância, que servem particularmente aos interesses e estratégias de grandes aparatos empresariais, financeiros, político e militares. Se a pós-verdade, instanciada na balbúrdia babélica das redes sociais, tem uma virtude, é a de escancarar a impotência, sobretudo nas periferias do capitalismo, do Estado de Direito como máquina capaz de reduzir a violência, as desigualdades, as

15 Como o demonstra à exaustão a judicialização da política e a politização do judiciário, cujo exemplo recente mais marcante é a prisão de um ex-presidente da República através de um processo eivado de abusos de poder, escutas inconstitucionais, vazamentos ilegais de informação, midiatização e partidarismo político.

16 Ver Clastres, P. La société contre l'État, Paris: Les éditions de Minuit, 1974 e Ceppas, F. "Anthropophagie pour une éducation émancipatrice", in Le Télémaque, Presses Universitaires de Caen, No52, 2017, p.109-118.

17 Lévi-Strauss, C. Tristes Trópicos, SP: Cia. das Letras, 1996. p.413s. 
injustiças. Não se trata de negar que apenas podemos consertar o barco em

pleno oceano. Nada do que dissemos tem compromisso com um desprezo pela política institucional em si, ou com a crença ingênua, reacionária, de que o Estado corrupto é o grande responsável por todos males, etc. O que defendemos, somente, é que o Estado e o Direito jamais serão capazes sequer de amenizar o pesadelo da pós-verdade. Se isso é verdade, o que dizer do ensino de filosofia?

A questão não é tanto se a filosofia pode promover uma reinvenção do pensamento crítico perante os conteúdos publicados e consumidos na internet, evitando a armadilha de uma disputa inútil em torno da Verdade. Nem se seria possível integrar o ensino de filosofia à internet, utilizando as redes - em meio (e como alternativa) ao bombardeio de suas (des)informações e fakenews - como ferramenta para promover a ação dos regimes de verdade, com suas temporalidades outras. A dinâmica da pós-verdade não atua apenas através de apelos emocionais, estéticos e ideológicos, promovendo cortinas de fumaça para esconder os interesses daqueles que produzem fakenews; ela torna seus adversários reféns desse modus operandi apelativo. Como fugir dessa armadilha em seu interior? Nossa aposta é que a filosofia, o exercício dos regimes de verdade próprios à filosofia, pode, sem dúvida, ajudar a desconstruir o pesadelo da pós-verdade apenas na medida em que assuma não existir qualquer crítica contra ele fora de uma crítica radical ao capitalismo, à democracia burguesa e à própria internet tal como ela hoje funciona, enquanto principal plataforma de controle da recente fase do capitalismo tardio.

\section{Referências}

CEPPAS, F. "Arte, educação e emancipação”, AISTHE, Vol. VII, no 11, 2013.

CEPPAS, F. "Anthropophagie pour une éducation émancipatrice", in Le Télémaque, Presses Universitaires de Caen, No52, 2017, p.109-118.

CLASTRES, P. La société contre l'État, Paris, Les éditions de Minuit, 1974.

FOUCAULT, M. "Os intelectuais e o poder. Entrevista entre Michel Foucault e Gilles Deleuze", in Microfísica do poder, trad. R. Machado, Rio de Janeiro: Graal, 1979.

GUALANDI, A. Lyotard, trad. A. Skinner, São Paulo: Estação Liberdade, 2007.

HAN, B-C. A agonia do Eros, trad. E. P. Giachini - Petrópolis, RJ: Editora Vozes, 2017.

LÉVI-STRAUSS, C. Tristes Trópicos, trad. R.F. D’Aguiar, São Paulo: Cia. das Letras, 1996. 
MBEMBE A. Politiques de l'inimitié, Paris: Éditions La Découverte, 2016.

NIETZSCHE, F. Humano, demasiado humano, trad. P.C Souza, São Paulo: Cia. das Letras, 2005.

OXFORD DICTIONARY, Disponível em: < https://en.oxforddictionaries.com/word-of-the-year/word-of-the-year-2016 >

ROUVROY, A; BERNS, T. Governamentalidade algoritmica e perspectivas de emancipação: o díspar como condição de individuação pela relação? In: Revista Eco Pós, vol. 18, n. 2, pp. 35-56, 2015.

ROUVROY, A. "Mise en (n)ombres de la vie même : face à la gouvernementalité algorithmique, repenser le sujet comme puissance", Mediapart, 2012. Disponível em: < https://blogs.mediapart.fr/antoinette-rouvroy/blog/270812/mise-en-nombres-de-la-vie-meme-face-la-gouvernementalite-algorithmique-repenser-le-sujet-com > RANCIÈRE, J. "Emancipación intelectual y educación hoy", in GONZÁLEZ, P. y CELEDÓN, G. (orgs), Reflexiones con Jacques Rancière, Valparaíso: Ed. UV de la Universidad de Valparaíso, 2016.

RANCIÈRE, J. La méthode de l'égalité, Paris: Bayard, 2012.

RANCIÈRE, J. O mestre ignorante, cinco lições sobre a emancipação intelectual, trad. L. Valle, Belo Horizonte: Autêntica, 2002.

RANCIÈRE, J. "École, Production, Égalité". In X. Renou (ed.), Lécole de la démocratie. France, Paris : Edilig Fondation Diderot, 1998.

RANCIÈRE, J. "Os riscos da razão", entrevista, Folha de São Paulo, 10 de setembro de 1995. Disponível em: < http://almanaque.folha.uol.com.br/entrevista_filosofia_jacques_ranciere.htm > 